\title{
Creep-Fatigue Interaction Life Consumption of Industrial Gas Turbine Blades
}

\author{
Ebigenibo Genuine Saturday ${ }^{1}$, Thank-God Isaiah ${ }^{2}$ \\ ${ }^{1}$ Department of Mechanical Engineering, University of Port Harcourt, Port Harcourt, Nigeria \\ ${ }^{2}$ Department of Mechanical Engineering, Niger Delta University, Wilberforce Island, Amassoma, Nigeria \\ Email: satebi@yahoo.com
}

How to cite this paper: Saturday, E.G. and Isaiah, T.-G. (2018) Creep-Fatigue Interaction Life Consumption of Industrial Gas Turbine Blades. Modern Mechanical Engineering, 8, 221-232.

https://doi.org/10.4236/mme.2018.84015

Received: September 15, 2018

Accepted: October 14, 2018

Published: October 19, 2018

Copyright $\odot 2018$ by authors and Scientific Research Publishing Inc. This work is licensed under the Creative Commons Attribution International License (CC BY 4.0).

http://creativecommons.org/licenses/by/4.0/

\begin{abstract}
This paper presents the creep-fatigue interaction life consumption of industrial gas turbine blades using the LM2500+ engine operated at Pulrose Power station, Isle of Mann as a case study. The linear damage summation approach where creep damage and fatigue damage are combined was used for the creep-fatigue interaction life consumption of the target blades. The creep damage was modelled with the Larson-Miller parameter method while fatigue damage was assessed with the modified universal slopes method and the damage due to creep-fatigue interaction was obtained from the respective life fractions. Because of the difficulty in predicting the life of engine components accurately, relative life consumption analysis was carried out in the work using the concept of creep-fatigue interaction factor which is the ratio of the creep-fatigue interaction life obtained from any condition of engine operation to a reference creep-fatigue interaction life. The developed creep-fatigue interaction life consumption analysis procedure was applied to 8 most of real engine operation. It was observed that the contribution of creep to creep-fatigue interaction life consumption is greater than that of fatigue at all ambient temperatures. The fatigue contribution is greater at lower ambient temperatures as against higher ambient temperatures. For the case study, the overall equivalent creep-fatigue factor obtained was 1.5 which indicates safe engine operation compared to the reference condition. The developed life analysis algorithm could be applied to other engines and could serve as useful tool in engine life monitoring by engine operators.
\end{abstract}

\section{Keywords}

Creep Damage, Fatigue Damage, Creep-Fatigue Interaction, Creep-Fatigue Interaction Factor

\section{Introduction}

Gas turbine blades, especially the compressor turbine blades of aero derivative 
turbines are exposed to high temperatures and can fail due to creep [1] [2] [3]. Although, creep might be the most dominant mode of failure, but if gas turbines are operated and shut down often, in some cases daily, fatigue failure will equally set in [4] [5]. Turbine blades failure in such cases may not be solely due to creep or fatigue, but may occur in the form of creep-fatigue interaction which is a combined mode of failure [6] [7]. There are several methods of investigating the creep-fatigue interaction failure of engine components. Creep-fatigue failure acting starts with a crack growth and most of methods employed centres on crack growth rate/propagation. Andrew and Potirniche [8], Narasimhachary and Saxena [9], and many other researchers [10] [11] [12] [13] considered creep-fatigue crack growth in determining the creep-fatigue interaction failure of different components.

Aside the crack growth approach, there several other methods of investigating creep-fatigue interaction failure. Zhu et al. [6] exploited a generalized energy-based damage parameter approach in predicting the creep-fatigue interaction failure of turbine disk alloys. Chen et al. [14] exploited the principles of energy and momentum conservations in developing a model for creep-fatigue interaction life prediction. Mao and Mahadevan [15] proposed a reliability model for creep and fatigue in materials with the creep-fatigue failure expressed in terms of creep and fatigue damage parameters. Creep-fatigue life prediction often involves experimentation and data about creep-fatigue interaction behaviour of many materials is available [16] [17]. Sometimes, oxidation of materials is considered in addition to creep-fatigue interaction failure [18]. This is borne out of the nature of the environment the engine is being operated. Thermo-mechanical fatigue is sometimes used to represent creep-fatigue-oxidation interaction in materials.

Creep-fatigue interactions can usually be modelled exploiting two widely used approaches. These are the isothermal method and the linear damage summation approach. Creep and other effects are not taken into account in the isothermal method. The linear damage summation rule takes the contributions of creep and fatigue and it is more or less combining the Palmgren-Miner rule for fatigue [19] and the Robinson's rule for creep [20] under various combination of stress and temperature exploiting the life fraction rule as presented by Zhuang and Swanson [21]. The linear damage summation rule was used in this work where creep damage was modelled with Larsson-Miller parametric method [22], and fatigue failure was determined using the modified universal slopes method [23].

It is difficult to obtain very accurate results in life prediction of components. Also, fatigue life is stochastic in nature [24] [25], hence there is need to predict the life of components where the life obtained at a given condition is relative to the life at a reference condition especially in engine operation. In creep life prediction, Addul-Ghafir et al. [26] introduced the concept of creep factor in analysing engine creep life consumption where creep factor is the ratio of the predicted engine life to a reference life. The concept of fatigue factor was by Saturday and Thank-God [4] in analysing the fatigue failure of industrial gas turbine 
blades. Following same trend, in this work, the concept of creep-fatigue interaction factor is used, where creep-fatigue interaction factor is the ratio of the creep-fatigue interaction life at any point or time frame of engine operation to the creep-fatigue interaction life at a reference point of engine operation. The creep-fatigue interaction life prediction methodologies was applied to real engine operation data using LM2500+ engine operated at Isle of Mann as a case study. Thus, in this work, a method of creep-fatigue interaction analysis which could be applied to gas turbines and track the life consumption of the blades has been developed.

\section{Methodology}

The linear damage accumulation method is applied in this work; hence the creep and the fatigue terms are considered separately and combined. The Larson-Miller parameter method is used for the creep while the modified universal slopes method is used for the fatigue life component. Blade thermal and stress models developed for the analysis together with creep-fatigue interaction model all incorporated in PYTHIA [27], Cranfield University in-house gas turbine performance analysis and diagnostics software. The analysis is done by exploiting relative life analysis.

\subsection{Creep Life Model}

The creep life model employed is the Larson-Miller parameter method given by Equation (1),

$$
t_{f}=10^{\left(\frac{\mathrm{LMP}}{T}-C\right)}
$$

where $t_{f}$ is the time to creep failure, $T$ is the temperature of blade material in Kelvin (K), LMP is the Larson Miller parameter obtained from a Master curve and $C$ is material constant usually of the order of 20. The creep life is estimated by developing blade stress and thermal models and each blade is divided to several sections. Details of how the creep life could be estimated could be found in [1]. The life fraction consumed due to creep is,

$$
D_{c, i}=\frac{t_{i}}{t_{f, i}}
$$

where $t_{i}$ is the time spent at a given stress-temperature combination, $t_{f, i}$ is creep fracture life at same stress-temperature combination and $D_{c, i}$ is a parameter which represents the fraction of life consumed.

\subsection{Fatigue Life Model}

The fatigue life model adopted in this work is the modified universal slopes method which is expressed in terms of nominal alternating stress amplitude, $\sigma_{a}$ as,

$$
\sigma_{a}=0.623 \sigma_{u}^{0.832} E^{0.168}\left(2 N_{f}\right)^{-0.09}+0.0196 \varepsilon_{f}^{0.155} \sigma_{u}^{-0.53} E^{1.53}\left(2 N_{f}\right)^{-0.56}
$$


where $\sigma_{u}$ is the ultimate tensile strength of the material, $E$ is the Young's Modulus of the material, $\varepsilon_{f}$ is the true fracture ductility, and $N_{f}$ is the number of stress cycles to failure. The fraction of life consumed due to fatigue at each stress-temperature combination is given as,

$$
D_{f, i}=\frac{N_{i}}{N_{f, i}}
$$

where $D_{f, i}$ is a fatigue damage parameter, $N_{i}$ is the number of cycles accumulated at stress amplitude $\sigma_{a, i}$ and $N_{f, i}$ is the number of cycles to failure at stress amplitude $\sigma_{a, i}$. Fatigue life is estimated using a developed stress model of the blades and details could be found in [4].

\subsection{Creep-Fatigue Interaction Life Model}

Using the linear accumulation model, the creep-fatigue interaction life at a given stress-temperature combination is expressed in terms of creep-Fatigue damage parameter $D_{c+f}$ given by Equation (5),

$$
D_{c+f}=\frac{t_{i}}{t_{f, i}}+\frac{N_{i}}{N_{f, i}}
$$

For a given period of engine operation, the creep-fatigue damage parameter will be the sum of the creep damage terms and the fatigue damage terms as in Equation (6),

$$
D_{c+f}=\sum \frac{t_{i}}{t_{f i}}+\sum \frac{N_{i}}{N_{f i}}
$$

The value of the creep-fatigue damage parameter ranges from zero to unity, and failure occurs at unity.

At any point of engine operation where the engine is operated for time $t_{i}$, the time to creep-fatigue interaction failure $t_{f, c+f}$ is,

$$
t_{f, c+f}=\frac{t_{i}}{D_{c+f, i}}=\frac{t_{i}}{\frac{t_{i}}{t_{f, i}}+\frac{N_{i}}{N_{f, i}}}
$$

Equation (7) could also be expressed in terms of cycles to failure $N_{f, c+f}$ as,

$$
N_{f, c+f}=\frac{N_{i}}{D_{c+f, i}}=\frac{N_{i}}{\frac{t_{i}}{t_{f, i}}+\frac{N_{i}}{N_{f, i}}}
$$

The damage parameter could be extended to any period of engine operation; hence, the time to creep-fatigue failure as well as the number of cycles to creep-fatigue interaction failure could be estimated for any period of engine operation. This is termed equivalent creep-fatigue life (ECFL) as given by Equations (9),

$$
\mathrm{ECFL}=\frac{\sum_{i=1}^{m} t_{i}}{D_{c+f}}=\frac{\sum_{i=1}^{m} t_{i}}{\sum_{i=1}^{m} \frac{t_{i}}{t_{f, i}}+\sum_{i=1}^{m} \frac{N_{i}}{N_{f, i}}}
$$


Equations (7) to (9) are obtained using that creep-fatigue interaction failure occurs when the creep-fatigue damage parameter is unity. No engine operator ever envisage to operate his engine to failure hence if creep-fatigue interaction failure of an engine component is tracked, parts are likely replaced when the value of $D_{c+f}$ obtained is close to unity. Also, it is difficult to predict engine life accurately; this necessitates comparing the life obtained to a reference life.

\subsection{Creep-Fatigue Interaction Factor}

Creep-fatigue interaction factor is used to assess the severity of engine operation under creep-fatigue interaction life consumption; this is similar to the fatigue factor approach [26], and the fatigue factor approach [4]. The creep-fatigue interaction factor at any point of engine operation is expressed by Equation (10),

$$
\mathrm{CFF}=\frac{t_{f, c+f}}{t_{f, c+f \_\operatorname{Re} f}}
$$

where CFF is the creep-fatigue interaction factor, $t_{f, c+f_{-} \operatorname{Re} f}$ is the time to creep-fatigue interaction failure at a reference point. For a complicated engine operation process involving different conditions and time frames of engine operation, the equivalent creep-fatigue interaction factor (ECFF) is used and this is given by Equation (11),

$$
\mathrm{ECFF}=\frac{\mathrm{ECFL}}{t_{f, c+f_{-} \operatorname{Re} f}}
$$

Equation (10) and Equation (11) could also be presented in terms of cycles to failure.

\subsection{Integrated Creep-Fatigue Interaction Life Analysis System}

The creep-fatigue interaction analysis system developed in this work is shown in Figure 1. It has PYTHIA at centre with creep life analysis and fatigue life analysis sub-systems providing inputs to the creep-fatigue interaction life analysis system. Details of the creep life analysis procedure could be found in [1] while fatigue life analysis procedure and system is presented in [4]. An engine model which behaves like the real engine in the field is created in PYTHIA for the life analysis as in [1].

Both creep-life consumption and fatigue life consumption are carried out in their respective life analysis systems in Figure 1 before creep-fatigue interaction analysis is executed. The results of creep life analysis and fatigue life analysis are passed to the creep-fatigue analysis system and each of the life analysis systems communicates with PYTHIA where engine model properties as well as simulated engine performance values are obtainable.

\section{Results}

The results of the creep-fatigue interaction life consumption could be in terms of time to failure or cycles to failure. But, they are presented in terms of relative engine 


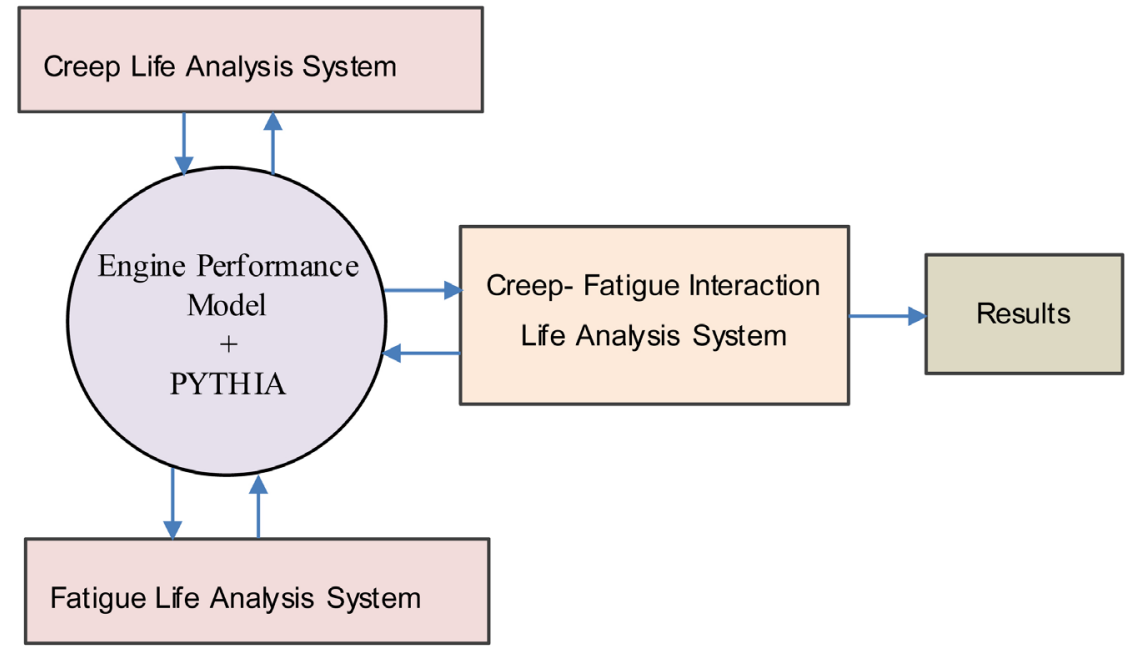

Figure 1. Creep-fatigue interaction analysis system.

life consumption which is creep-fatigue interaction factor. The creep-fatigue interaction life consumption procedure developed in this work was applied to 8 different months of real engine operation. The aim is to track the engine life. The creep-fatigue interaction life of the hot section blades of LM2500+ engine operated in Isle of Mann was tracked in this work. The equivalent creep-fatigue factor for each day operation of the engine for the 8 different months of engine operation is shown in Figure 2.

During the months of January, February, March, and December where low ambient temperatures are recorded, the creep-fatigue interaction factors obtained are higher as in Figure 2. On the other hand, in the months of June, July and August where the ambient temperature is high, lower values of equivalent creep-fatigue interaction factors are obtained. The results in November are also low, because high ambient temperatures were recorded in many days of engine operation in November. The above occurrence is because industrial turbine blade failure is more likely to occur due to creep as against fatigue. The contribution of creep to the creep-fatigue interaction failure for daily shut down of engine is much higher compared to the fatigue contribution. In low ambient temperatures, creep life consumption is slower; hence creep-fatigue interaction consumption is also slower. Large values of equivalent creep-fatigue factor indicate safe engine operation and vice-versa.

The equivalent creep-fatigue interaction factor for each month is shown in Figure 3. Also, the overall equivalent creep-fatigue interaction factor (OECFF) for the entire 8 months considered is also presented in Figure 3. The equivalent creep-fatigue factor for each month is greater than 1, this means favourable engine operation in the entire period with respect to creep-fatigue interaction failure at a reference operation point. The lowest equivalent creep-fatigue factor, 1.03 was recorded in July, a bit safe operation. This is the month with highest ambient temperatures and lowest creep factor values as in [1]. The overall equivalent creep-fatigue factor for the entire period of engine operation is 1.5. 


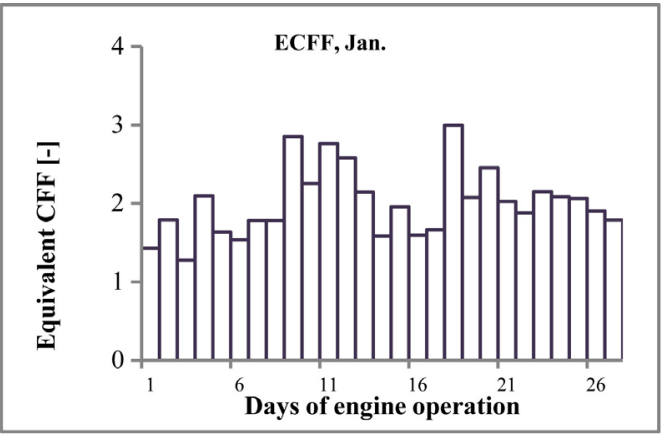

(a)

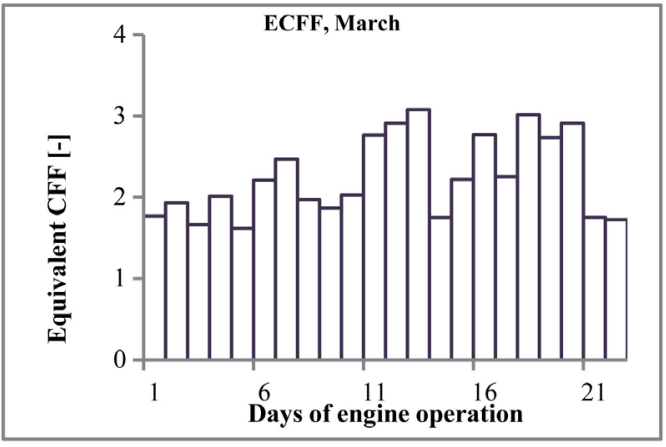

(c)

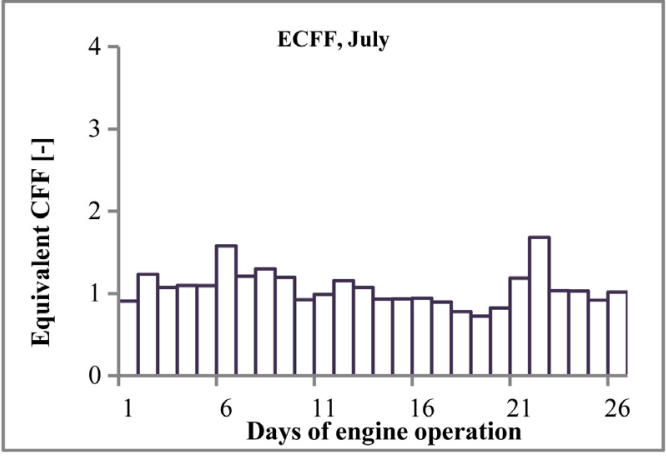

(e)

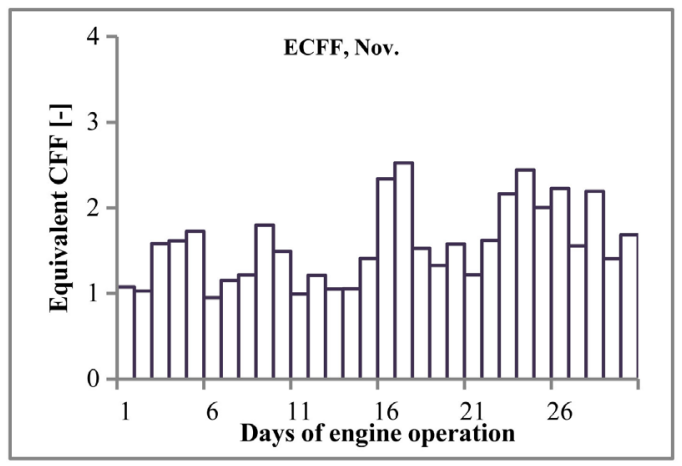

(g)

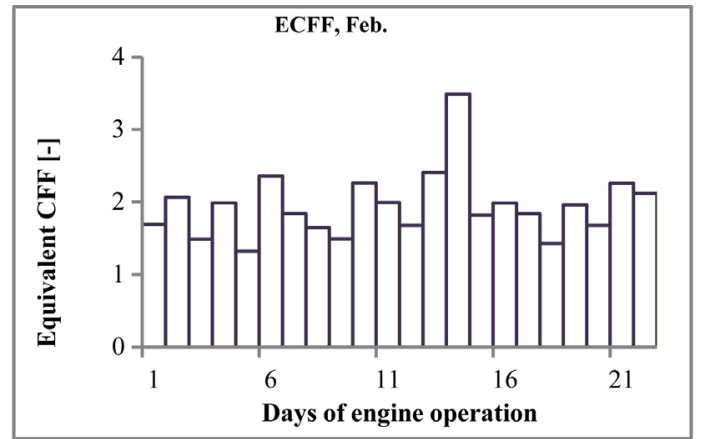

(b)

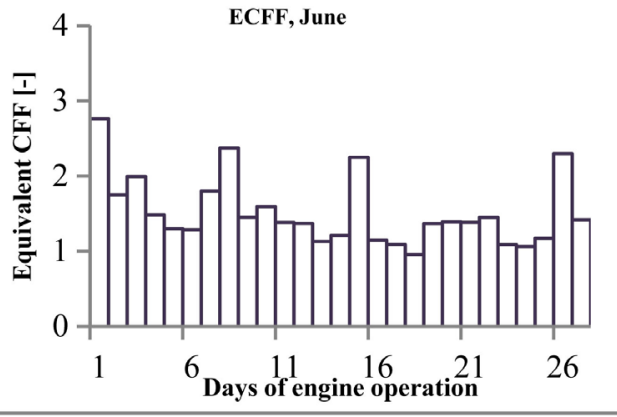

(d)

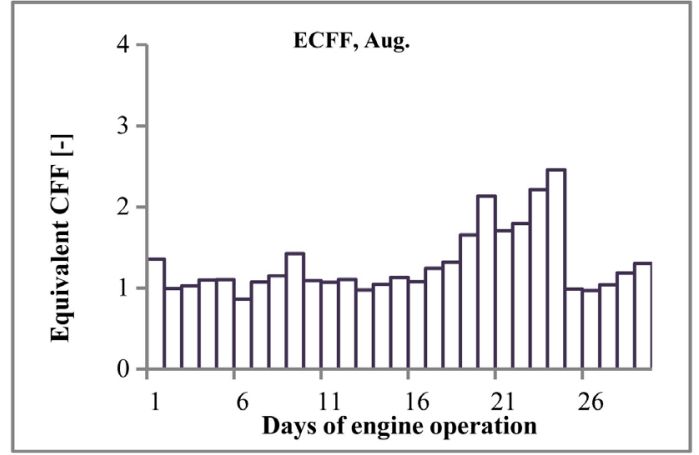

(f)

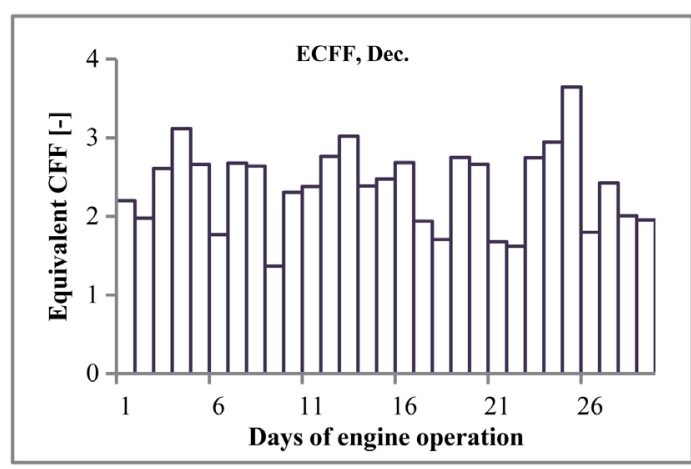

(h)

Figure 2. Equivalent creep-fatigue factors for 8 different months of engine operation.

This indicates that the life consumption rate due to creep-fatigue interaction is $50 \%$ less compared to the reference engine operation condition. The engine operation in the entire period is thus favourable. 


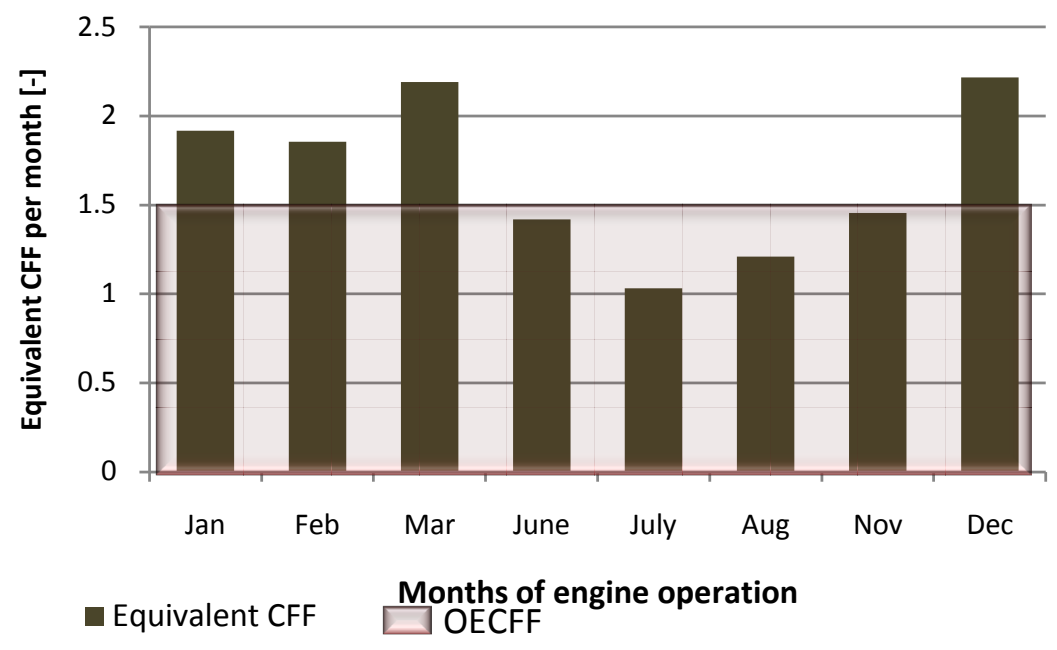

Figure 3. Equivalent creep-fatigue factors for each month of engine operation.

In order to show the dominance of creep life consumption in creep-fatigue interaction life consumption, the equivalent creep factors (ECF) and equivalent creep-fatigue factors for two different months (January with low ambient temperature and July with high ambient temperatures) of engine operation are compared as in Figure 4. In both months of engine operation, the equivalent creep-fatigue interaction factors closely approximate the equivalent creep factors for each day of engine operation. The contribution of creep becomes more dominant in periods of high ambient temperatures. The equivalent creep factors are thus closer to the equivalent creep-fatigue factors in July of engine operation (Figure 4(b)) than in January (Figure 4(a)).

\section{Low Cycle Fatigue Contribution to Creep-Fatigue Interaction}

The creep-fatigue interaction life consumption in each month of engine operation is greater than the creep life consumed because of the presence of fatigue life consumption in the former. If creep life consumption is used as base life consumption, the additional life consumed in creep-fatigue interaction life consumption may be viewed as reduction in engine life. Figure 5 shows the percentage reduction in engine life using creep life consumption as base life for the 8 different months considered. As may be expected, the life reduction is higher in the months with lower ambient temperatures where fatigue life consumption is higher if even is shut down often.

The percentage reduction in life is evaluated taking creep life as the base life. As creep interacts with fatigue, the resultant life is less than the creep life and the decrease in life due to fatigue contribution decreases with an increase in fatigue factors. The reduction in life is highest in the months with low ambient temperatures where fatigue contributions are highest. At the conditions where creep dominance is more paramount, the results of creep life consumption is not much different from those of creep-fatigue interaction life consumption. Thus in such engine operation conditions, estimating only creep life consumption may 


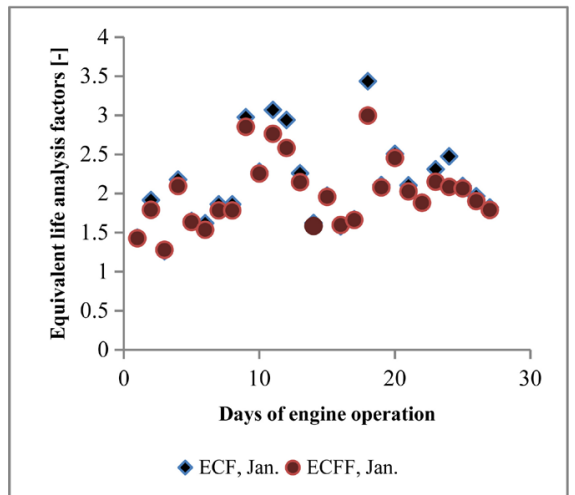

(a)

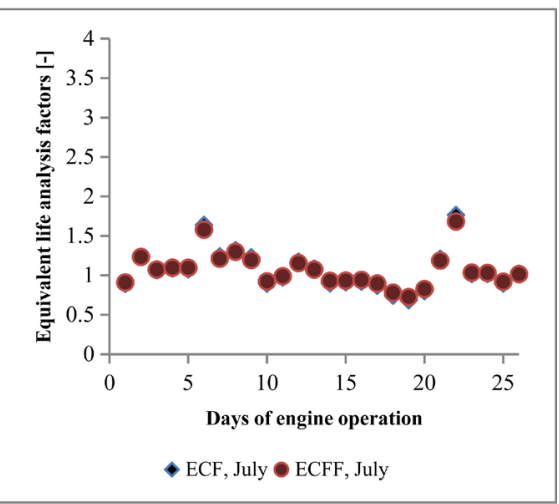

(b)

Figure 4. Comparison of equivalent creep factors and equivalent creep-fatigue factors in two months of engine operation.

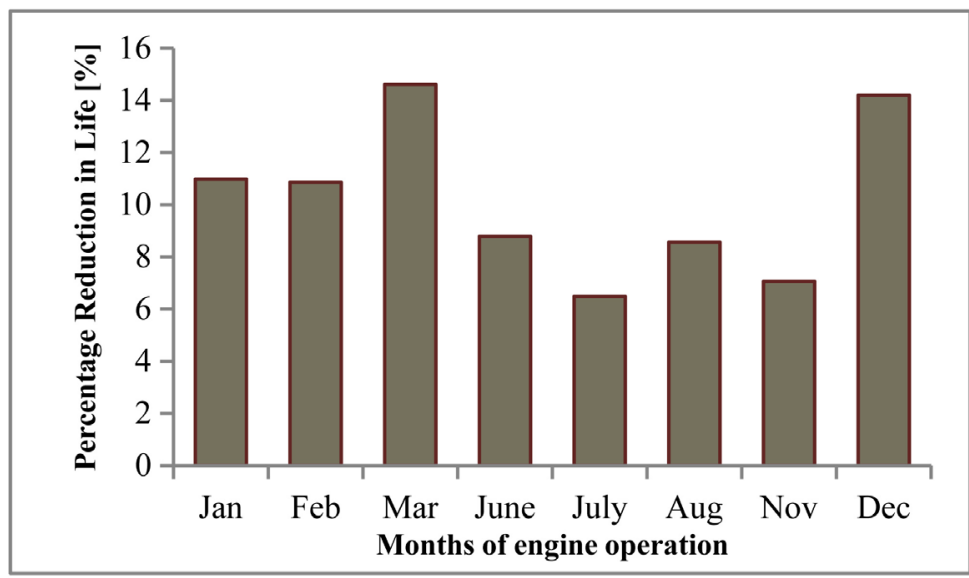

Figure 5. Percentage reduction in life due to fatigue interaction with creep.

be sufficient. Generally, during high ambient temperature and low part load operation, creep life estimation alone may suffice.

\section{Conclusion}

Creep-fatigue interaction life analysis is considered in this work exploiting the linear creep and fatigue accumulation model. Creep fatigue analysis system and fatigue life analysis system developed in previous works are used to provide inputs to the creep-fatigue interaction life analysis system to track the creep-fatigue interaction life consumption of LM2500+ engine operated at Isle of Mann. In the 8 months of engine operation considered, using relative life analysis, the months with low ambient temperatures have high values of creep-fatigue interaction factor indicating safer engine operation. Creep dominates the creep-fatigue failure at the different conditions the engine was operated. This is expected as industrial gas turbines are operated in a bit stable power conditions and fatigue cycles accumulated over time are quite few. Also, the fatigue contribution to creep-fatigue interaction life is higher in the months with lower ambient temperature if engine is often shut down. As fatigue interacts with creep, about $10 \%$ 
reduction the life was obtained on the average for the average for the 8 months considered. As much as $14.5 \%$ life reduction was obtained in the months of March and December. The results obtained are in line with what is obtainable in real engine operation and the life tracking methodology developed could be applied to any engine. The effects of ambient temperature variation, shaft power level and engine degradation on creep-fatigue interaction life need to be investigated.

\section{Conflicts of Interest}

The authors declare no conflicts of interest regarding the publication of this paper.

\section{References}

[1] Saturday, E.G., Li, Y.G., Ogiriki, E.A. and Newby, M.A. (2017) Creep-Life Usage Analysis and Tracking for Industrial Gas Turbines. Journal of Propulsion and Power, 33, 1305-1314. https://doi.org/10.2514/1.B35912

[2] Vaezi, M. and Soleymani, M. (2009) Creep Life Prediction of Inconel 738 Gas Turbine Blade. Journal of Applied Sciences, 9, 1950-1955. https://doi.org/10.3923/jas.2009.1950.1955

[3] Marahleh, G., Kheder, A.R.I. and Hamad, H.F. (2006) Creep-Life Prediction of Service-Exposed Turbine Blades. Materials Science, 42, 476-481. https://doi.org/10.1007/s11003-006-0103-8

[4] Saturday, E.G. and Isaiah, T. (2018) Low Cycle Fatigue Life Estimation and Tracking for Industrial Gas Turbine Blades Using Fatigue Factor Approach. Modern Mechanical Engineering, 8, 111-120. https://doi.org/10.4236/mme.2018.82008

[5] Harmon, D., Mcclure, M., Grelotti, R. and Hartford, E. (2010) Unified Low Cycle Fatigue for Gas Turbine Engine Rotor Alloys. Proceedings of 51 st AIAA/ASME/ ASCE/AHS/ ASC Structures, Structural Dynamics, and Materilas Conference, Orlando, 12-15 April 2010, 1-10.

[6] Zhu, S., Huang, H., He, L., Liu, Y. and Wang, Z. (2012) A Generalized Energy-Based Fatigue-Creep Damage Parameter for Life Prediction of Turbine Disk Alloys. Engineering Fracture Mechanics, 90, 89-100. https://doi.org/10.1016/j.engfracmech.2012.04.021

[7] Pierce, C.J., Palazotto, A.N. and Rosenberger, A.H. (2010) Creep and Fatigue Interaction in the PWA1484 Single Crystal Nickel-Base Alloy. Materials Science and Engineering: A, 527, 7484-7489. https://doi.org/10.1016/j.msea.2010.08.033

[8] Andrews, B.J. and Potirniche, G.P. (2015) Constitutive Creep-Fatigue Crack Growth Methodology in Two Steels Using a Strip Yield Model. Engineering Fracture Mechanics, 140, 72-91. https://doi.org/10.1016/j.engfracmech.2015.03.042

[9] Narasimhachary, S.B. and Saxena, A. (2013) Crack Growth Behavior of 9Cr-1MO (P91) Steel under Creep-Fatigue Conditions. International Journal of Fatigue, 56, 106-113. https://doi.org/10.1016/j.ijfatigue.2013.07.006

[10] Bache, M.R., Johnston, R.E., Cook, T.S., Robinson, B.J. and Matlik, J.F. (2012) Crack Growth in the Creep-Fatigue Regime under Constrained Loading of thin Sheet Combustor Alloys. International Journal of Fatigue, 42, 82-87.

https://doi.org/10.1016/j.ijfatigue.2011.07.005 
[11] Hurley, P.J., Whittaker, M.T., Webster, P. and Evans, W.J. (2007) A Methodology for Predicting Creep/Fatigue Crack Growth Rates in Ti 6246. International Journal of Fatigue, 29, 1702-1710. https://doi.org/10.1016/j.ijfatigue.2007.01.014

[12] Shlyannikov, V.N., Tumanov, A.V. and Boychenko, N.V. (2015) A Creep Stress Intensity Factor Approach to Creep-Fatigue Crack Growth. Engineering Fracture Mechanics, 142, 201-219. https://doi.org/10.1016/j.engfracmech.2015.05.056

[13] Bouvard, J.L., Chaboche, J.L., Feyel, F. and Gallerneau, F. (2009) A Cohesive Zone Model for Fatigue and Creep-Fatigue Crack Growth in Single Crystal Superalloys. International Journal of Fatigue, 31, 868-879. https://doi.org/10.1016/j.ijfatigue.2008.11.002

[14] Chen, L., Jiang, J., Fan, Z., Chen, X. and Yang, T. (2007) A New Model for Life Prediction of Fatigue-Creep Interaction. International Journal of Fatigue, 29, 615-619. https://doi.org/10.1016/j.ijfatigue.2006.07.009

[15] Mao, H. and Mahadevan, S. (2000) Creep Fatigue Reliability of High Temperature Materials. 8th ASCE Specialty Conference on Probabilistic Mechanics and Structural Reliability, University of Notre Dame, 4-26 July 2000, 1-6.

[16] Hu, D. and Wang, R. (2009) Experimental Study on Creep-Fatigue Interaction Behavior of GH4133B Superalloy. Materials Science and Engineering. A, 515, 183-189.

[17] Chen, L.J., Yao, G., Tian, J.F., Wang, Z.G. and Zhao, H.Y. (1998) Fatigue and Creep-Fatigue Behavior of a Nickel-Base Superalloy at $850^{\circ} \mathrm{C}$. International Journal of Fatigue, 20, 543-548. https://doi.org/10.1016/S0142-1123(98)00022-X

[18] Fournier, A., Sauzay, B., Caes, M., Noblecourt, C., Mottot, M., Bougault, M., Rabeau, A. and Pineau, V. (2008) Creep-Fatigue-Oxidation Interactions in a $9 \mathrm{Cr}-1 \mathrm{Mo}$ Martensitic Steel. Part I : Effect of Tensile Holding Period on Fatigue Lifetime. International Journal of Fatigue, 30, 649-662. https://doi.org/10.1016/j.ijfatigue.2007.05.007

[19] Suresh, S. (2004) Fatigue of Materials. 2nd Edition, Cambridge University Press, New York.

[20] Robinson, S.L. (1952) Effect of Temperature Variation on the Long Time Rupture Strength of Steels. Transactions of ASME, 74, 777-780.

[21] Zhuang, W.Z. and Swansson, N.S. (1998) Thermo-Mechanical Fatigue Life Prediction: A Critical Review, DSTO-TR-0609. DSTO Aeronautical and Marine Research Laboratory, Melbourne Victoria.

[22] Larson, F.R. and Miller, J. (1952) Time-Temperature Relationship for Rupture and Creep Stresses. Transactions of ASME, 74, 765-771.

[23] Park, J. and Song, J. (1995) Detailed Evaluation of Methods for Estimation of Fatigue Properties. International Journal of Fatigue, 17, 365-373. https://doi.org/10.1016/0142-1123(95)99737-U

[24] Sapsard, M. (2000) Recommended Practices for Monitoring Gas Turbine Engine Life Consumption, RTO/NATO-NASA. Canada Communication Group Inc.

[25] Zhang, R. (2001) Reliability-Based Reassessment of Corrosion Fatigue Life. Structural Safety, 23, 77-91. https://doi.org/10.1016/S0167-4730(01)00002-9

[26] Abdul Ghafir, M.F., Li, Y.G., Wang, L. and Zhang, W. (2011) Impact Analysis of Aero-Engine Performance Parameter Variation on Hot Section's Creep Life Using Creep Factor Approach. AIAA, 16, 1-12.

[27] Li, Y.G. and Singh, R. (2005) An Advanced Gas Turbine Gas Path Diagnostic System-PYTHIA. 17th International Symposium on Air Breathing Engines, Munich, 1-12. 


\section{Nomenclature}

\begin{tabular}{|c|c|}
\hline$C$ & Material constant \\
\hline $\mathrm{CFF}$ & Creep-fatigue interaction factor \\
\hline ECFF & Equivalent creep-fatigue interaction factor \\
\hline ECFL & Equivalent creep-fatigue life \\
\hline LMP & Larson Miller parameter \\
\hline$T$ & Temperature of blade material \\
\hline$D_{c, i}$ & Creep life fraction consumed \\
\hline$D_{f, i}$ & Fatigue damage parameter \\
\hline$D_{c+f}$ & Creep-Fatigue interaction damage parameter \\
\hline$E$ & Young's Modulus of the material \\
\hline$N_{f}$ & Number of stress cycles to failure \\
\hline$N_{f, i}$ & Number of cycles to failure \\
\hline$N_{f, c+f}$ & Number of cycles to creep-fatigue interaction failure \\
\hline$N_{i}$ & Number of cycles accumulated \\
\hline$t_{f}$ & Time to creep failure \\
\hline$t_{f, i}$ & creep fracture life at same stress-temperature combination \\
\hline$t_{f, c+f}$ & Time to creep-fatigue interaction failure \\
\hline$t_{f, c+f_{-} \mathrm{Re} f}$ & Time to creep-fatigue interaction failure at a reference point \\
\hline$t_{i}$ & Time spent at a given stress-temperature combination \\
\hline$\varepsilon_{f}$ & True fracture ductility \\
\hline$\sigma_{a}$ & Nominal alternating stress amplitude \\
\hline$\sigma_{u}$ & Ultimate tensile strength of the material \\
\hline
\end{tabular}

